Davies, D. A. L. (1958). J. gen. Microbiol. 18, 118-128

\title{
The Smooth and Rough Somatic Antigens of Pasteurella pseudotuberculosis
}

\author{
By D. A. L. DAVIES \\ Microbiological Research Establishment, Porton, Wiltshire
}

SUMMARY : From strains of Pasteurella pseudotuberculosis representing each of the five serological groups and some 'Rough' forms, lipopolysaccharides were isolated after disintegration of acetone-dried saline extracted organisms with phenol. The materials appear to carry the specificities on which the serological classification of the species is based; they are relatively poor antigens when isolated but antigenicity can be enhanced by combining with lipoprotein. Analyses show some unusual features, an aldoheptose sugar being present in all of the materials and some of the 'Smooth' cell products contain dideoxy sugars; rhamnose is absent. The 'Rough' cell products are somewhat similar in composition to the 'Rough' somatic polysaccharide of Pasteurella pestis, to which they are also related serologically.

The principal antigenic features and the basis of the present serological classification of Pasteurella pseudotuberculosis were established by Schütze $(1928,1932)$. Strains were classified into three serological groups by bacterial agglutination, heat-stable Smooth ' $\mathrm{O}$ ' somatic antigens analogous to those of the Salmonellas being postulated to account for this. Another heat-stable component was common to all 'Smooth' and 'Rough' strains of $\boldsymbol{P}$. pseudotuberculosis and extended also to $P$. pestis; this was attributed to a Rough ' $R$ ' somatic antigen. Flagellar ' $\mathrm{H}$ ' antigen was common to all $P$. pseudotuberculosis strains but absent from $P$. pestis.

This serological work was amplified by Thal (1954); a large number of strains (186) were allotted to their serological groups and only two could not be accommodated in groups I-III of Schütze (1928). These also differed from one another and were classified in two new groups IV and V. It is well known that certain strains of Pasteurella pseudotuberculosis produce a powerful heatlabile toxin and such strains were shown to be confined to group III. This exotoxin differs from that of $\boldsymbol{P}$. pestis (Schar \& Thal, 1955). The group IV strain differed from all other 'Smooth' strains in being avirulent, but it is of interest to note that when injected alive into guinea pigs this group IV strain was able to protect against infection by members of other serological groups and also against plague infection (Thal, 1956). Rough avirulent strains obtained from different groups could not be distinguished serologically from each other since they possessed the 'Rough' somatic specificity present also in the Smooth forms and in $P$. pestis.

This general picture appears to be very similar to the situation found among the Enterobacteriaceae but no antigens have been isolated having the properties described. Extraction of Pasteurella pseudotuberculosis cells with trichloroacetic acid (Boivin \& Mesrobeanu, 1935; Girard, 1941), or with diethyleneglycol (Schar \& Thal, 1955) failed to yield an endotoxin ('O' 
somatic antigen). Some work in this laboratory is being directed towards a clarification of such serological findings by chemical characterization of the substances responsible. In the Pasteurella group the ' $R$ ' somatic antigen of $P$. pestis has already been described (Davies, 1956); this substance can be extracted from any strain whether rough or smooth, virulent or avirulent, toxic or non-toxic, etc., which confirms Schütze's postulate that this species is basically 'Rough' in the Salmonella sense. Evidence for the individuality of a number of other antigens has been given by Crumpton \& Davies (1956 $a$ ) who showed that six antigens were common to $\boldsymbol{P}$. pseudotuberculosis and $\boldsymbol{P}$. pestis; one of these has now been described in more detail (Crumpton \& Davies, 1957) and others are being examined.

In spite of the failures to extract typical 'endotoxins' the heat stability of the Pasteurella pseudotuberculosis group specific components does suggest the presence of polysaccharides and the inability to detect group specific proteins (Crumpton \& Davies, to be published) supports this view. Lazarus \& Nozawa (1948) obtained toxic phage lysates but there was no indication as to the nature of the toxic substance. Thal (1954) was able to obtain group specific precipitin reactions using warm saline extracts of agar grown cells.

In the present paper the isolation and some properties of the 'Smooth' group specific and 'Rough' somatic antigens are described; their serological properties are dealt with more fully in the following paper (Crumpton, Davies \& Hutchison, 1958).

\section{METHODS}

Organisms. Strains belonging to each of the five serological groups of Pasteurella pseudotuberculosis were very kindly supplied by Dr Thal (Veterinärmedizinischen Staatsinstitut, Stockholm). These were maintained on agar slopes (tryptic meat digest agar with peptic sheep's blood). Rough strains of certain groups were isolated from plates by using the same medium. The serological groups numbered I, II, III, ..., by previous workers have, in accordance with the recommendations of the International Bacteriological Code of Nomenclature, been referred to herein by letters A, B, C, .... Thus, for example, the Smooth state of strain number 25 in group $\mathrm{V}$ and the Rough state of strain number 74 from group I (Thal, 1954) are designated $25 / \mathrm{E} / \mathrm{S}$ and $74 / \mathrm{A} / \mathrm{R}$, respectively.

Growth and recovery of organisms. Bacteria were grown in tryptic meat broth containing $1 \%$ (w/v) galactose (Ross, Hakes \& Herbert, private communication); $250 \mathrm{ml}$. amounts of medium were dispensed in 'Thompson' bottles (Gallenkamp and Co., London, E.C. 4). These were inoculated with $1 \mathrm{ml}$. (1 mg. dry wt. organisms) of a saline suspension of the given organism which had been grown for $18 \mathrm{hr}$. on agar slopes. Incubation for $40 \mathrm{hr}$. on a reciprocating shaker at $37^{\circ}$ gave yields varying from 3 to $8 \mathrm{~g}$. dry wt./l. in different cases. Organisms were recovered by centrifuging at $20,000 \mathrm{~g}$, resuspended in a small volume of cold water and poured into $10 \mathrm{vol}$. of acetone at $-20^{\circ}$. After several changes of cold acetone the organisms were dried in vacuo over $\mathrm{H}_{2} \mathrm{SO}_{4}$.

Materials for analysis. Samples of extraction products for analysis were 
thoroughly dialysed against distilled water at $0-2^{\circ}$ and dried from the frozen state. They were further dried to constant weight in vacuo at $78^{\circ}$ before making into aqueous solutions of known concentration.

Nitrogen and phosphorus estimations. Nitrogen was determined by the microKjeldahl method, using the distillation apparatus of Markham (1942); phosphorus was estimated on samples containing $5-30 \mu \mathrm{g}$. P by a modification of the method of Fiske \& Subbarow (1925).

Sugars. Hexosamine was measured by the Elson \& Morgan (1933) method and aldoheptose according to Dische (1953).

Chromatography. Polysaccharide samples were hydrolysed in sealed ampoules at $100^{\circ}$ with $\mathrm{N}-\mathrm{H}_{2} \mathrm{SO}_{4}$ for $15 \mathrm{hr}$. and neutralized with $\mathrm{Ba}(\mathrm{OH})_{2}$. The neutral salt-free solutions were evaporated to dryness in vacuo and redissolved at suitable concentrations for application to paper chromatograms. Whatman No. 1 paper was used with a variety of solvent systems (Davies, 1957a); papers were sprayed with Ehrlich's reagent (Partridge, 1948) to reveal 2-amino sugars, or with anisidine hydrochloride (Hough, Jones \& Wadman, 1950) which distinguishes by colour the different classes of reducing sugars.

Nucleic acid. The nucleic acid content of extraction products was estimated by measuring in a Unicam ultraviolet spectrophotometer the absorption at $260 \mathrm{~m} \mu$. of material dissolved in $0.05 \mathrm{~N}-\mathrm{NaOH}$. A purified preparation of ribonucleic acid (RNA) was used as a standard for reference.

Ultracentrifugation. High-speed centrifuge runs were carried out in a Spinco Model ' $L$ ' preparative ultracentrifuge and analytical runs in a Spinco Model ' $\mathrm{E}$ ' machine.

Antisera. Antisera were prepared in rabbits by the intravenous injection of extraction products dissolved in sterile saline. Injections were given weekly until examination of serum samples indicated that the required antibodies had been formed. Sera against whole living organisms were prepared by similar methods in white rats, which are not susceptible to Pasteurella pseudotuberculosis infection.

Precipitation reactions. Antigens and antisera were examined by the agar diffusion precipitin technique of Ouchterlony (1953) as used by Crumpton \& Davies $(\mathbf{1 9 5 6} a$ ). Precipitation in fluid medium was carried out as described by Davies (1956).

Toxicity and pyrogenicity. Tests were performed according to Davies, Morgan \& Mosimann (1954) and Davies (1956), respectively.

\section{RESULTS}

Saline extraction

Extraction of acetone-dried organisms with water yielded material very largely protein in nature. More complete extraction of the surface proteins could be made with saline $(2.5 \%, \mathrm{w} / \mathrm{v})$ as used by Baker et al. (1952). Batches of organism (c. $50 \mathrm{~g}$.) of each of five 'Smooth' strains and four 'Rough' strains were suspended in saline $(1 \mathrm{l}$.$) and stirred for 24 \mathrm{hr}$. at $20^{\circ}$, toluene being added to prevent mould and bacterial growth. Suspensions were centrifuged at 
$12,000 \mathrm{~g}$ for $2 \mathrm{hr}$. and the sediment resuspended in water, poured into $10 \mathrm{vol}$. of acetone at $-10^{\circ}$ and subsequently dried. The saline supernatant solutions were dialysed until free from salt and freeze dried; the products were preserved for study of the protein antigens they contained, which were mainly antigens 2, 4, 5, 6 and 7 (Crumpton \& Davies, 1956 $a$ ); these will be described in subsequent communications. These extracts contained little carbohydrate and nucleic acid amounted to not more than $5 \%$.

\section{Phenol extraction}

Samples of organism recovered after saline extraction were treated with diethyleneglycol (Morgan, 1937; Morgan \& Partridge, 1940; Davies et al. 1954), with aqueous pyridine (Goebel, Binkley \& Perlman, 1945), with aqueous glycerol (Binkley, Goebel \& Perlman, 1945) or phenol (Westphal, Lüderitz \& Bister, 1952). Only in the phenol extracts were significant yields of carbohydrate obtained.

The bulk of the organisms recovered from each saline extract were therefore extracted by the phenol method, being suspended at $10 \%(\mathrm{w} / \mathrm{v})$ concentration in water and heated to $65^{\circ}$. An equal vol. of phenol $(90 \%, \mathrm{w} / \mathrm{v})$ at the same temperature was added and the single phase system stirred at this temperature for $20 \mathrm{~min}$. Suspensions were then cooled to $2^{\circ}$ and centrifuged at this temperature to hasten the separation of water and phenol phases. The small amount of sediment obtained was composed of protein and DNA. The phenol phase contained denatured protein and the aqueous phase contained soluble carbohydrate and degraded RNA. The aqueous phase was poured into $10 \mathrm{vol}$. of acetone at $-10^{\circ}$ and the precipitated material redissolved in water and precipitated by adding 2 vol. ethanol. This precipitate was redissolved at $c .1 \%$ $(\mathrm{w} / \mathrm{v})$ concentration and centrifuged at $100,000 \mathrm{~g}$ for $4 \mathrm{hr}$. Degraded RNA was thus left in the supernatant fluid and the sedimented material was redissolved and centrifuged in the same way until the ultraviolet adsorption of a sample showed the nucleic acid content to be no more than $1-2 \%$. The final sedimented fractions proved to be lipopolysaccharides which differed considerably in solubility from different strains, so that some of the relatively insoluble ones (e.g. 32/D/R) were obtained in better yield and quite free from nucleic acid. The more soluble preparations (e.g. $27 / \mathrm{C} / \mathrm{S}$ ) were obtained in smaller yield, a considerable amount of polysaccharide remaining in the nucleic acid fraction.

Nucleic acid was recovered from the centrifuged supernatant fluids by dialysis and freeze-drying. Further amounts of polysaccharide could be recovered from these fractions by other methods (ethanol fractionation, acid precipitation, ribonuclease), but the original centrifuge sediments recovered by dialysis and freeze-drying were used in the present work. Some data for these materials are shown in Table 1. The weights recorded are not related to true yields with respect to cell content, since in all cases some polysaccharide remained in the nucleic acid fractions. The actual yields of lipopolysaccharide in the aqueous phase of the phenol extracts was estimated to be in the range of $1-3 \%$ of the dry weight of organism. 
Table 1. Lipopolysaccharides obtained by phenol extraction of Pasteurella

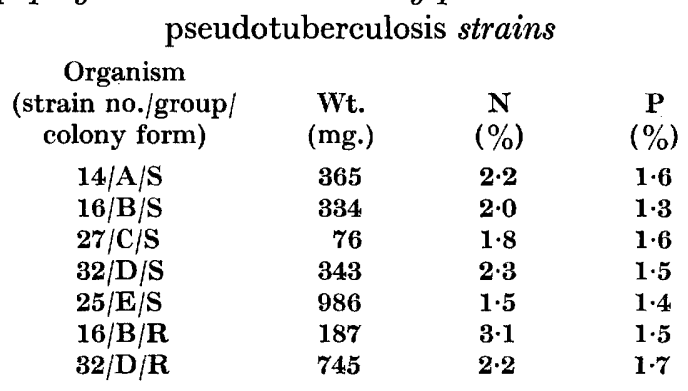

\section{Carbohydrate fractions}

Composition. By analogy with materials, of similar $\mathbf{N}$ and $\mathbf{P}$ content and other properties, previously obtained from various Gram-negative organisms by the phenol extraction method (e.g. Westphal et al. 1952), the products were expected to be lipopolysaccharides. This was checked with two samples $(25 / \mathrm{E} / \mathrm{S}$ and $32 / \mathrm{D} / \mathbf{R})$ which were degraded by heating with dilute acetic acid as already described (Davies, 1955). The acetic acid-insoluble material which separated was also insoluble in ether but dissolved in chloroform and appeared to be entirely analogous to the chloroform-soluble phospholipids which have been fully described (Westphal \& Lüderitz, 1954) from similar extracts of various species of Enterobacteriaceae. From the acetic acid supernatant solution a degraded polysaccharide hapten could be recovered by precipitation with ethanol.

Homogeneity. The presence of less than $2 \%$ nucleic acid could be demonstrated in the lipopolysaccharides by examination of their ultraviolet absorption spectra; ribose was not detected on paper chromatograms when hydrolysates were examined for their sugar constituents as described below. The absence of free protein follows from the method of extraction wherein such material is denatured by warm phenol. This was confirmed by failure of the products to give any protein reactions, their low $\mathbf{N}$ content similar to that of better characterized lipopolysaccharides (Davies, 1956), the presence of only traces of ninhydrin reactive material other than amino sugar in hydrolysates examined on paper chromatograms and which can be accounted for as products of the degradation of the lipid moiety, and lack of ultraviolet absorption in the region of $280-290 \mathrm{~m} \mu$.

Owing to the poor solubility of lipopolysaccharides extracted by the phenol method, demonstration of physical homogeneity is extremely difficult. Solubility in salt solution is poorer than in water, but in cases where electrophoretic examination has been possible (Davies, Morgan \& Record, 1955) there has clearly been a very small net charge. It therefore seemed permissible to carry out ultracentrifuge runs in water, this was done in the present work with the more soluble preparations which sedimented as single components.

Degradation with acetic acid has been referred to above, the extent depending upon the types of glycosidic linkages present and varying with different 
materials (Davies et al. 1955; Davies, 1956). It might therefore be expected that a mixture of lipopolysaccharides which failed to resolve on ultracentrifugal analysis might be separable after such degradation. A degraded polysaccharide hapten preparation obtained from $25 / \mathrm{E} / \mathrm{S}$ lipopolysaccharide by treatment with $1 \%(\mathrm{w} / \mathrm{v})$ acetic acid at $100^{\circ}$ for $3 \mathrm{hr}$. in a nitrogen atmosphere, and subsequent separation from the phospholipid component, was examined in the analytical ultracentrifuge, and a single sedimentation boundary was revealed. These results were quite insufficient evidence of homogeneity but were possible indications in that direction.

Important for the purposes of the present work was an indication of whether the materials were immunologically homogeneous. A suggestion that this might be the case was deduced from gel diffusion experiments. Each lipopolysaccharide reacted with a serum prepared by immunization with organisms of the homologous strain, and in each case a single line of precipitation was formed. These sera contained antibodies which reacted with all the major antigenic components of the original organisms. Sera prepared by injecting lipopolysaccharide which had been combined with lipoprotein (Partridge \& Morgan, 1940; Davies, 1956) reacted with the homologous lipopolysaccharide and also with whole organisms of the homologous serological group, to give only one line of precipitation. With the five 'Smooth' group products the five lines indicated different specificities since they were in no instance contiguous when reacting from adjacent reservoirs. No cross-reaction was detected on diffusion plates between 'Smooth' and 'Rough' products nor between 'Smooth' Pasteurella pseudotuberculosis polysaccharides and P. pestis 'Rough' somatic polysaccharide.

Chromatographic analysis. The sugar constituents of lipolysaccharides extracted from the various groups are shown in Table 2. Estimates of the amount of aldoheptose present are in terms of D-glycero-L-mannoheptose (Davies, 1957a); in the method of estimation used different heptose sugars give different amounts of absorption and a true estimate can be made only when the identity of a sugar is known. The chromatographic behaviour of the heptose component was the same for each of the polysaccharides shown in Table 2, but although this resembled D-glycero-L-mannoheptose or its optical enantiomorph in some respects, its true identity is not yet established. Estimates of total amino sugar are shown in Table 2 , it should be noted that glucosamine is not necessarily a component of the polysaccharide moiety since it is known to be a constituent of the phospholipid.

\section{Biological properties}

Antigenicity. Although antibodies to the polysaccharides can readily be obtained by immunizing rabbits with killed whole organisms, or by injecting rats with living organisms, the isolated lipopolysaccharides were poorly antigenic. Their antisera failed to precipitate the homologous materials in fluid media and gave no line of precipitation when tested by the agar diffusion precipitin method. A definite antigenic response was, nevertheless, detected by the more sensitive haemagglutination technique with red cells sensitized 
with the corresponding polysaccharide as described by Crumpton et al.(1958). Precipitating antisera were obtained by injecting lipopolysaccharide combined with the lipoprotein component of the Shigella dysenteriae somatic antigen as used by Davies (1956). This method was used for each of the materials extracted and gave monospecific antisera, whereas in the sera prepared in rats by immunization with living organisms the main response had clearly been directed against protein antigens (Crumpton \& Davies, to be published).

Table 2. Sugar constituents of Pasteurella pseudotuberculosis polysaccharides

\begin{tabular}{|c|c|c|c|c|c|c|c|c|c|c|c|c|}
\hline $\begin{array}{c}\text { Organism } \\
\text { (strain no./group/ } \\
\text { colony form) }\end{array}$ & 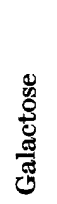 & 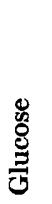 & 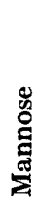 & 怨 & 兽 & 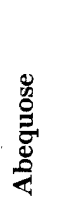 & 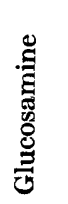 & 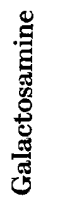 & 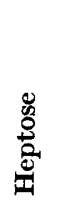 & $\begin{array}{l}\text { Heptose* } \\
\text { content } \\
(\%)\end{array}$ & $\begin{array}{c}\text { Hexosamine } \\
\text { content } \\
(\%)\end{array}$ & $\begin{array}{c}\text { Unidentified } \dagger \\
\text { components }\end{array}$ \\
\hline $14 / \mathrm{A} / \mathrm{S}$ & + & + & . & . & . & . & + & . & + & $\mathbf{5}$ & $4 \cdot 3$ & 1 \\
\hline $16 / \mathrm{B} / \mathrm{S}$ & + & + & + & . & . & + & + & . & + & 17 & $9 \cdot 5$ & . \\
\hline $27 / \mathrm{C} / \mathrm{S}$ & . & + & + & + & . & . & + & + & + & 13 & $5 \cdot 0$ & 1 \\
\hline $32 / \mathrm{D} / \mathrm{S}$ & . & . & + & . & + & . & + & + & + & 19 & $6 \cdot 3$ & . \\
\hline $25 / \mathrm{E} / \mathrm{S}$ & . & + & + & + & + & . & + & + & + & 18 & $7 \cdot 5$ & . \\
\hline $74 / \mathrm{A} / \mathrm{R}$ & . & + & . & . & . & . & + & . & + & & & . \\
\hline $16 / \mathrm{B} / \mathrm{R}$ & . & + & . & . & . & . & + & . & + & 5 & $5 \cdot 0$ & . \\
\hline $43 / C / R$ & . & + & . & . & . & . & + & . & + & 17 & & . \\
\hline $32 / \mathrm{D} / \mathrm{R}$ & . & . & . & . & . & . & + & . & + & 26 & $9 \cdot 5$ & . \\
\hline
\end{tabular}

With lipopolysaccharide + lipoprotein induced antisera against the products of each of the 5 groups and also 2 Rough strains, each material was tested by tube precipitation against each serum. These results are shown in Table 3. Each serum reacted most strongly with its homologous lipopolysaccharide, and the group specificities appear to be carried by these materials. Considerable cross-reactions occurred, however, especially with the Rough strain products. In some instances stronger precipitation was found in heterologous reactions

\section{Table 3. Precipitin reactions of Pasteurella pseudotuberculosis lipopolysaccharides}

Sera were prepared by immunization of rabbits with isolated lipopolysaccharides combined with 'Shiga' lipoprotein. Results are expressed as the sum of up to 3 points for degree of precipitation in each tube showing a reaction. Serum undiluted, lipopolysaccharide in serial 1/2 dilutions beginning at 1/7260.

\begin{tabular}{|c|c|c|c|c|c|c|c|}
\hline \multirow{2}{*}{$\begin{array}{c}\text { Antigen } \\
\text { group }\end{array}$} & \multicolumn{7}{|c|}{ serum group } \\
\hline & $\mathbf{A} / \mathbf{S}$ & $\mathbf{B} / \mathbf{S}$ & $\mathrm{C} / \mathrm{s}$ & $\mathrm{D} / \mathrm{S}$ & $\mathbf{E} / \mathbf{S}$ & $\mathbf{B} / \mathbf{R}$ & $\mathbf{D} / \mathbf{R}$ \\
\hline $14 / A / S$ & 5 & 2 & $\mathbf{0}$ & 5 & 3 & 2 & 2 \\
\hline $16 / \mathrm{B} / \mathrm{S}$ & $\mathbf{0}$ & 13 & $\mathbf{0}$ & 8 & 4 & $\mathbf{3}$ & 5 \\
\hline $27 / \mathrm{C} / \mathrm{S}$ & $\mathbf{0}$ & $\mathbf{3}$ & 6 & 6 & 3 & 2 & $\mathbf{3}$ \\
\hline $32 / D / S$ & 1 & 3 & $\mathbf{0}$ & 14 & 6 & $\mathbf{3}$ & $\mathbf{3}$ \\
\hline $25 / \mathrm{E} / \mathrm{S}$ & $\mathbf{0}$ & 1 & $\mathbf{0}$ & 4 & 11 & 1 & $\mathbf{3}$ \\
\hline $16 / \mathrm{B} / \mathrm{R}$ & 1 & 5 & 0 & 6 & 4 & 4 & 4 \\
\hline $32 / D / R$ & 2 & 6 & $\mathbf{0}$ & 10 & 5 & 4 & 8 \\
\hline
\end{tabular}


where the homologous serum was relatively weak. Some Rough strain products also precipitated with Pasteurella pestis antisera.

Because of difficulty in interpreting these results and also on account of the poor solubility of some of the preparations, a more extensive serological examination was carried out by the more sensitive and versatile haemagglutination method. These results are recorded in the following paper (Crumpton et al. 1958).

Toxicity and pyrogenicity. Like the somatic antigens prepared from members of the Enterobacteriaceae, the Pasteurella pseudotuberculosis lipopolysaccharides are toxic for mice, but whereas the former generally have a LD 50 dose in the range of 20-100 $\mu \mathrm{g}$. the present materials had a LD 50 dose of about $500 \mu \mathrm{g}$. There was a suggestion, however, that effective toxicity was dependent to some extent on state of dispersion since the LD 50 dose was decreased to 200$300 \mu \mathrm{g}$. after heating solutions at $80^{\circ}$ for $5 \mathrm{~min}$. This heat treatment gave a stable opalescent solution of those materials which were otherwise unstable cloudy suspensions. A similar effect was noted with respect to pyrogenic potency. Lipopolysaccharide $\mathbf{3 2} / \mathbf{D} / \mathbf{R}$ was particularly insoluble and was pyrogenic in rabbits at $1 \mu \mathrm{g} . / \mathrm{kg}$. rabbit; after heat treatment a significant pyrogenic response was obtained at $0.005 \mu \mathrm{g} . / \mathrm{kg}$. rabbit, a figure more in keeping with those of other pyrogens.

\section{DISCUSSION}

In the course of examining the antigens of Pasteurella pestis it was observed that the organism shared a number of antigens with $P$. pseudotuberculosis, and most of these were already known to be proteins (Crumpton \& Davies, 1956a). When $\boldsymbol{P}$. pseudotuberculosis strains of different serological groups were compared by the agar diffusion precipitin method no differences were found between the protein antigen line patterns which would account for the serological grouping. This agreed with the observations of Schütze (1928) that heatstable antigens were responsible for the serological group specificities. It was noted, however, that all avirulent strains, whether rough or smooth, lacked one protein antigen (Crumpton \& Davies, 1957).

The presence of surface protein antigens, as, for example, in Pasteurella pestis, makes the extraction of polysaccharides more difficult (Davies, 1956); the same situation exists in $\boldsymbol{P}$. pseudotuberculosis where the somewhat drastic phenol method was finally chosen. The products of this extraction method are poor antigens but their serological specificity seems unimpaired; they are variable in their state of aggregation and it should be noted that this affects the measurement of some biological activities. A disadvantage of using poorly soluble materials of this type is that a satisfactory demonstration of physical homogeneity is precluded, and with the amounts of fractions available only circumstantial evidence of homogeneity has been obtained. However, there are indications that 'Rough' lipopolysaccharide may not be present in smooth organisms. The sugars present in the 'Rough' products are also present in the 'Smooth' products, but this is clearly not contamination since some of the latter contain, for example, more aldoheptose sugar and glucosamine than some of the former. The 'Rough' polysaccharides are themselves only qualitatively similar, and their close constitutional relationship to $P$. pestis 
polysaccharide is of interest. It seems likely, therefore, that the ' $S$ ' and ' $R$ ' antigens of Schütze (1932) and Thal (1954) are not discrete chemical entities, but that the ' $R$ ' somatic specificity is due to a part of the structure of the ' $S$ ' antigen. The view of Schütze (1932) that $P$. pestis shares a common ' $R$ ' somatic specificity with $P$. pseudotuberculosis could also be reconciled with this interpretation.

A situation found in Shigella dysenteriae may not be dissimilar from that in Pasteurella pseudotuberculosis. The ' $O$ ' somatic antigen contains galactose, glucosamine and rhamnose (Morgan, 1938); no cross-reaction occurs between rough and smooth cell products but a 'Rough' polysaccharide has now been described (Davies, 1957b) which contains galactose, glucosamine and an aldoheptose. No 'Rough' component could be detected in smooth organisms which again suggests that the $\mathbf{S} \rightarrow \mathbf{R}$ change reflects a change in polysaccharide constitution and not the loss of a 'Smooth' polysaccharide to reveal beneath a substance similar to that exposed on the surface of rough organisms. It is noteworthy that in the Enterobacteriaceae virulent organisms usually possess polysaccharides which contain deoxy sugars (rhamnose, fucose, tyvelose or abequose), these are not present in avirulent forms. This is also true of the Pasteurellas studied except that $\boldsymbol{P}$. pestis does not produce such a sugar, and $\boldsymbol{P}$. pseudotuberculosis $32 / \mathrm{D} / \mathrm{S}$ does so. In the latter it is known, however, that an important protein antigen is missing (Crumpton \& Davies, 1957), while in the former protein antigens known to be important in pathogenicity are produced (Crumpton \& Davies, 1956a, Burrows \& Bacon, 1956).

It might be noted that at the time of writing all polysaccharides extracted from rough forms of Gram-negative bacteria and which have been adequately analysed have proved to contain aldoheptose sugars. The identity of sugars recorded in Table $\mathbf{2}$ should be regarded as provisional since the information is based, apart from amino sugar and heptose, on chromatography alone. This is insufficient for final identification, more particularly in view of the number of new sugars which have recently been identified (e.g. Westphal \& Lüderitz, 1953; Strange, 1956; Crumpton \& Davies, 1956b; van Tamelen et al. 1956; MacLennan \& Davies, 1956; Muir, 1957; Fouquey, Polonsky \& Lederer, 1957). The dideoxy sugars in two instances could not be identified with any confidence. The absence of rhamnose is noteworthy, this sugar being widely distributed in bacterial polysaccharides.

Since this work was completed, the sugar constituents of a polysaccharide obtained from an unspecified strain of Pasteurella pseudotuberculosis have been reported by Sasaki (1957). This material differed in all its main features from the lipopolysaccharides described herein: xylose, arabinose and rhamnose were recorded, sugars notably absent from the preparations described above, whereas tyvelose, abequose and aldoheptose were not detected.

I am greatly indebted to Dr E. Thal for providing the strains of Pasteurella pseudotuberculosis, to Dr B. R. Record and Mr K. A. Cammack for ultracentrifugal analyses, Dr B. Whaler for carrying out pryogen tests and Mr V. S. G. Baugh for technical assistance. The interest and encouragement of $\mathrm{Dr} \mathrm{D}$. W. Henderson has been much appreciated. 


\section{REFERENCES}

Baker, E. E., Sommer, H., Foster, L. E., Meyer, E. \& Meyer, K. F. (1952). Studies on immunization against plague. I. The isolation and characterization of the soluble antigen of Pasteurella pestis. J. Immunol. 68, 131.

Binkley, F., Goeber, W. F. \& Perlman, E. (1945). Studies on the Flexner group of dysentery bacilli. II. The chemical degradation of the specific antigen of type $Z$ Shigella paradysenteriae (Flexner). J. exp. Med. 81, 331.

Borvin, A. \& Mesrobeanu, L. (1935). Recherches sur less antigènes somatique et sur les endotoxines bactériennes. I. Considérations générales et exposée des techniques utilisée. Rev. Immunol. 1, 553.

Burrows, T. W. \& Bacon, G. A. (1956). The basis of virulence in Pasteurella pestis: an antigen determining virulence. Brit. J. exp. Path. 37, 481.

Crumpton, M. J. \& Davies, D. A. L. (1956a). An antigenic analysis of Pasteurella pestis by diffusion of antigens and antibodies in agar. Proc. Roy. Soc. B, 145, 109.

Crumpton, M. J. \& Davies, D. A. L. (1956b). A new amino sugar present in the specific polysaccharides of some strains of Chromobacterium violaceum. Biochem. J. 64, $22 \mathrm{P}$.

Crumpton, M. J. \& Davies, D. A. L. (1957). A protein antigen associated with smooth colony forms of some Pasteurellas. Nature, Lond. 180, 863.

Crumpton, M. J., Davies, D. A. L. \& Hutchison, A. M. (1958). The sero ogical specificities of Pasteurella pseudotuberculosis somatic antigens. J. gen. Microbiol. $18,129$.

Davies, D. A. L. (1955). The specific polysaccharides of some Gram-negative bacteria. Biochem. J. 59, 696.

Davies, D. A. L. (1956). A specific polysaccharide of Pasteurella pestis. Biochem. J. $63,105$.

Davies, D. A. L. (1957 a). The identification of aldoheptose sugars. Biochem. J.67, 253.

Davies, D. A. L. $(\mathbf{1 9 5 7} b)$. Isolation of a rough somatic antigen from Shigella dysenteriae. Biochim. biophys. Acta, 26, 151.

Davies, D. A. L., Morgan, W. T. J. \& Mosimann, W. (1954). Studies in immunochemistry. 13. Preparation and properties of the ' $O$ ' somatic antigen of Shigella dysenteriae (Shiga). Biochem. J. 56, 572.

Davies, D. A. L., Morgan, W. T. J. \& Record, B. R. (1955). Studies in immunochemistry. 15. The specific polysaccharide of the dominant ' $O$ ' somatic antigen of Shigella dysenteriae. Biochem. J. 60, 290.

Dische, Z. (1953). Qualitative and quantitative colorimetric determination of heptoses. J. biol. Chem. 204, 983.

Elson, L. A. \& Morgan, W. T. J. (1933). A colorimetric method for the determination of glucosamine and chondrosamine. Biochem. J. 27, 1824.

Fiske, C. H. \& Subbarow, Y. (1925). The colorimetric determination of phosphorus. J. biol. Chem. 66, 375.

Fouquey, C., Polonsky, J. \& Lederer, E. (1957). Sur la structure chimique de l'alcool ascarylique' isolé de Parascaris equorum. Bull Soc. Chim. biol., Paris, 39, 101.

GrRard, G. (1941). Absence d'antigène glucido-lipidique chez le bacille de la peste et le bacille de la pseudo-tuberculose des rongeurs. C.R. Soc. biol. Paris, 135, 1577.

Goebel, W. F., Binkley, F. \& Perlman, E. (1945). Studies on the Flexner group of dysentery bacilli. J. exp. Med. 81, 315.

Hough, L., Jones, J. K. N. \& Wadman, W. H. (1950). Quantitative analysis of mixtures of sugars by the method of partition chromatography. V. J. chem. Soc. p. 1702.

Lazarus, Q. S. \& Nozawa, M. M. (1948). The endotoxin of Pasteurella pseudotuberculosis. J. Bact. 56, 187. 
Maclennan, A. P. \& Davies, D. A. L. (1956). Isolation of D-glycero-D-galactoheptose from the specific polysaccharide of Chromobacterium violaceum (BN). Biochem. J. 63, $31 \mathrm{P}$.

MARKhAM, R. (1942). A steam distillation apparatus suitable for micro-Kjeldahl analysis. Biochem. J. 36, 790.

Morgan, W. T. J. (1937). Studies in immunochemistry. 2. The isolation and properties of a specific antigenic substance from $B$. dysenteriae (Shiga). Biochem.J. 31, 2003.

Morgan, W. T. J. (1938). Isolierung von d-Galaktose und l-Rhamnose aus dem Hydrolysat des spezifischen Polysaccharids von Bact. dysenteriae (Shiga). Helv. chim. Acta, 21, 469.

Morgan, W. T. J. \& Partridge, S. M. (1940). Studies in immunochemistry. 4. The fractionation and nature of antigenic material isolated from Bact. dysenteriae (Shiga). Biochem. J. 34, 169.

Murr, H. (1957). A new amino sugar in acid hydrolysates of chondroitin sulphate from hyaline cartilage. Biochem. J. 65, $33 \mathrm{P}$.

Ouchterlony, Ö. (1953). Antigen-antibody reactions in gels. Acta path. microbiol. scand. 32, 231.

Partridge, S. M. (1948). Filter paper partition chromatography of sugars. 1. General description and application to the qualitative analysis of sugars in apple juice, egg white and foetal blood of sheep. Biochem. J. 42, 238.

Partridge, S. M. \& Morgan, W. T. J. (1940). Immunization experiments with artificial complexes formed from substances isolated from the antigen of Bact. shigae. Brit. J. exp. Path. 21, 180.

SASAKI, T. (1957). Monosaccharide composition of the antigenic polysaccharide of Pasteurella pseudotuberculosis rodentium. Nature, Lond. 179, 920.

Schar, M. \& Thal, E. (1955). Comparative studies on toxins of Pasteurella pestis and Pasteurella pseudotuberculosis. Proc. Soc. exp. Biol., N.Y. 88, 39.

SchüTze, H. (1928). Bakterium pseudotuberculosis rodentium. Rezeptoranalyse von 18 Stämmen. Arch. Hyg. 100, 181.

Schütze, H. (1932). Studies on $B$. pestis antigens. II. The antigenic relationship of B. pestis and B. pseudotuberculosis rodentium. Brit. J. exp. Path. 13, 289.

Strange, R. E. (1956). The structure of an amino sugar present in certain spores and bacterial cell walls. Biochem. J. 64, 23 P.

Thal, E. (1954). Untersuchungen über Pasteurella pseudotuberculosis. Lund, Sweden: Berlingska Boktryckeriet.

Thal, E. (1956). Relations immunologiques entre Pasteurella pestis et Pasteurella pseudotuberculosis. Ann. Inst. Pasteur, 91, 68.

van Tamelen, E. E., Dyer, J. R., Carter, H. E., Pierce, J. V. \& Daniels, E. E. (1956). Structure of the amino sugar derived from streptothricin and streptolin B. J. Amer. chem. Soc. 78, 4817 .

Westphal, O. \& Lüderitz, O. (1953). Zur chemischen Analyse von Lipopolysacchariden gramnegativer Bakterien: neue Desoxyzucker sowie ein Beitrag zur chemischen Differenzierung einiger O-glatt und O-rauh-Formen. 6th Int. Congr. Microbiol. Rome, Abstr. 2, 22.

Westphal, O. \& Lüderitz, O. (1954). Chemische Erforschung von Lipopolysacchariden gramnegativer Bakterien. Angerw. Chem. 66, 407.

Westphal, O., Lüderitz, O. \& Bister, F. (1952). Über die Extraktion von Bakterien mit Phenol-Wasser. Z. Naturf. $7 b, 148$. 